\title{
The Morphology of Physiologically Identified GABAergic Neurons in the Somatic Sensory Part of the Thalamic Reticular Nucleus in the Cat ${ }^{1}$
}

\author{
C. T. YEN,,$^{*, 2}$ M. CONLEY, ${ }^{*, 3}$ S. H. C. HENDRY, ${ }^{*} \ddagger^{4}$ AND E. G. JONES ${ }^{\star} \ddagger^{5}$ \\ * James L. O'Leary Division of Experimental Neurolngy and Neurological Surgery and McDonnell Center for Studies of Higher Brain \\ Function. Washington University School of Medicine, St. Louis, Missouri 63110 and $\ddagger$ Department of Anatomy, California College of \\ Medicine, University of California, Irvine, California 92717
}

\begin{abstract}
Neurons with somatic sensory receptive fields were examined electrophysiologically in the thalamic reticular nucleus of the cat. All cells had receptive fields much larger than those of neurons in the ventral posterior nucleus and were driven by less readily defined somesthetic stimuli. Response latencies to peripheral or medial lemniscal stimulation were, on average, longer than in the ventral posterior nucleus and suggested activation of the reticular nucleus cells by collaterals of thalamocortical relay cell axons arising in the ventral posterior nucleus.

When injected intracellularly with horseradish peroxidase, reticular nucleus cells displayed thin axons with intrareticular collaterals and diffuse branches through much of the ventral posterior and posterior thalamic nuclei. Dendrites ended in processes resembling synaptic terminals.

Electron microscopic immunocytochemistry of the same part of the reticular nucleus revealed processes immunoreactive for glutamic acid decarboxylase and identifiable as both collateral axon terminals and presynaptic dendrites of GABAergic reticular nucleus cells. These synaptically linked reticular nucleus cells and, in addition, immunoreactive somata and presynaptic dendrites received synapses from at least three varieties of nonimmunoreactive profiles.
\end{abstract}

The thalamic reticular nucleus, a derivative of the embryonic ventral thalamus, is a purc population of GABAcrgic ncurons that covers the anterior, lateral, and much of the ventral surfaces of the

Received January 2, 1985; Revised February 27, 1985;

Accepted February 27, 1985

1 This work was supported by Grants NS21377 and NS20507 from the National Institutes of Health, United States Public Health Service, and in part by the Washington University, McDonnell Center. We thank Bertha McClure and Margaret Bates for technical help, and Dr. C. Brandon for kindly supplying antiserum to glutamic acid decarboxylase

${ }^{2}$ Present address: Department of Zoology, National Taiwan University, Taipei, Taiwan

${ }^{3}$ Present address: Department of Anatomy, Vanderbilt University School of Medicine, Nashville, TN 37232

${ }^{4}$ Present address: Department of Anatomy, California College of Medicine University of California, Irvine, Irvine, CA 92717.

${ }^{5}$ To whom reprint requests should be directed, at his present address: Department of Anatomy, California College of Medicine, University of California, Irvine, Irvine, CA 92717 dorsal thalamus in all mammals (see Jones, 1985). The reticular nucleus was demonstrated to undergo cellular degeneration following destruction of the telencephalon in one of the earliest studies of the thalarmus (Nissl, 1913). Laler il was shown that destruction of the cerebral cortex alone was sufficient to cause a cellular reaction in the nucleus (Chow, 1952; Rose, 1952). As a consequence, and for many years, the idea of the reticular nucleus as the ultimate relay in a diffuse ascending cortical activating system was widespread (e.g., see Jasper, 1960). It is now recognized, however, that the cellular reaction in the reticular nucleus after cortical lesions does not denote a direct projection from the reticular nucleus to the cerebral cortex but, rather, the close connectional relationship that the reticular nucleus has with the underlying dorsal thalamus (Jones, 1975).

Ramón y Cajal (1911) first demonstrated with the Golgi technique that axons of reticular nucleus cells enter the underlying dorsal thalamus. This was confirmed by Scheibel and Scheibel (1966), who emphasized the extensive intrathalamic ramifications of these axons. At about the same time, Carman et al. (1964) conclusively demonstrated the existence of a widespread cortical projection to the reticular nucleus but argued convincingly against the existence of a reticulocortical projection. When autoradiography and horseradish peroxidase (HRP) histochemistry were introduced as tracers for anatomical connectivity, it quickly became evident that corticothalamic fibers, passing to a particular dorsal thalamic nucleus, and thalamocortical fibers emanating from that dorsal thalamic nucleus, give rise to terminations in the same part of the reticular nucleus as they pass through it. Moreover, the axons of cells in this part of the reticular nucleus include in their terminal ramifications the dorsal thalamic nucleus from which they receive inputs (Jones, 1975). The thalamocortical axons have been demonstrated to give off collaterals in the reticular nucleus by intracellular injections in relay neurons of the dorsal lateral geniculate (Ahlsén et al., 1978; Ferster and LeVay, 1978; Friedlander et al., 1979, 1981; Stanford et al., 1983), and ventral posterior nucleus (Yen and Jones, 1983; Yen et al., 1985). The net effect of this pattern of connectivity is that regions ("sectors") of the reticular nucleus are dominated by relations with a particular dorsal thalamic nucleus and, thus, some parts can be construed as visual, somatic sensory, or auditory in function. These anatomical predictions (Jones, 1975; Montero et al., 1977) have been supported by single-unit studies showing that cells in particular sectors of the reticular nucleus have visual, auditory, or somatic sensory receptive fields and that there may even be crude topographic mapping of the relevaril receplive surlace in such a seclor (Sandersor, 1971; Sumitomo et al., 1976; Sugitani, 1979; Shosaku and Sumitomo, 1983; Hale et al., 1982; Pollin and Rokyta, 1982; Yen and Jones, 1983)

Reticular nucleus cells are known to be GABAergic from immu- 


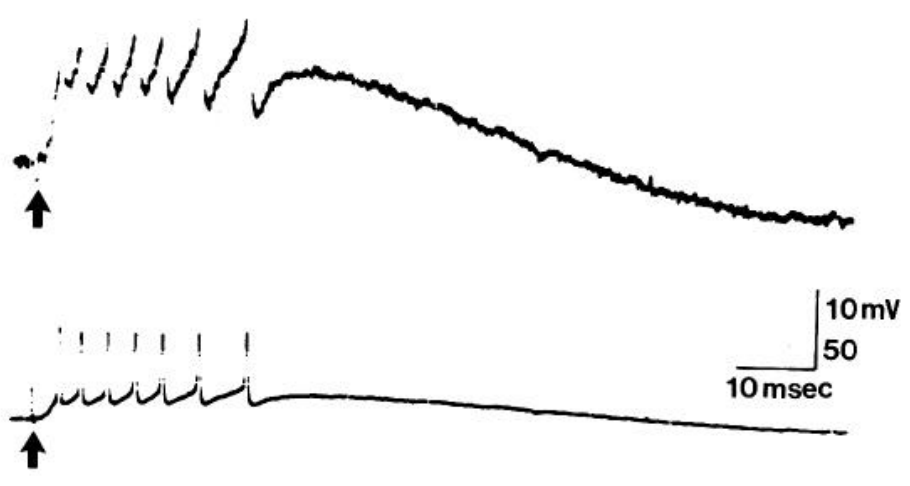

Figure 1. Typical intracellular record from a neuron in the somatic sensory part of the reticular nucleus, showing the large EPSP and train of spikes ensuing following a single 28-V, 20- $\mu$ sec electrical shock (arrow) applied to the arm area of the ipsilateral somatic sensory cortex. Upper trace, High gain $\mathrm{AC}$; lower trace, low gain $\mathrm{DC}$.

nocytochemical studies (Houser , 1980; Hendrickson et al., 1983; Oertel et al., 1983; Jones, 1985), and the terminals of their axons in the dorsal thalamus clearly make symmetric synaptic contacts and contain flattenable synaptic vesicles (Ohara et al., 1980, 1983; Montero and Scott, 1981), in keeping with their GABAergic and, therefore, presumably inhibitory nature. However, the overall morphology of the axons of reticular nucleus cells is still known only from the old Golgi studies, and the concept has developed that they are specifically distributed only to the dorsal thalamic nucleus with which they are functionally related (Hale et al., 1982) rather than more diffusely, as Golgi (Scheibel and Scheibel, 1966) and axon tracing methods had suggested (Minderhoud, 1971; Jones, 1975). We have, therefore, undertaken the present study in order to determine the morphology and distribution of axons arising from a defined functional grouping of reticular nucleus cells and to analyze some of the finer connectional features within the reticular nucleus itself. A brief preliminary report (Yen and Jones, 1983) has appeared, and other data from the same material are presented in a recent monograph (Jones, 1985).

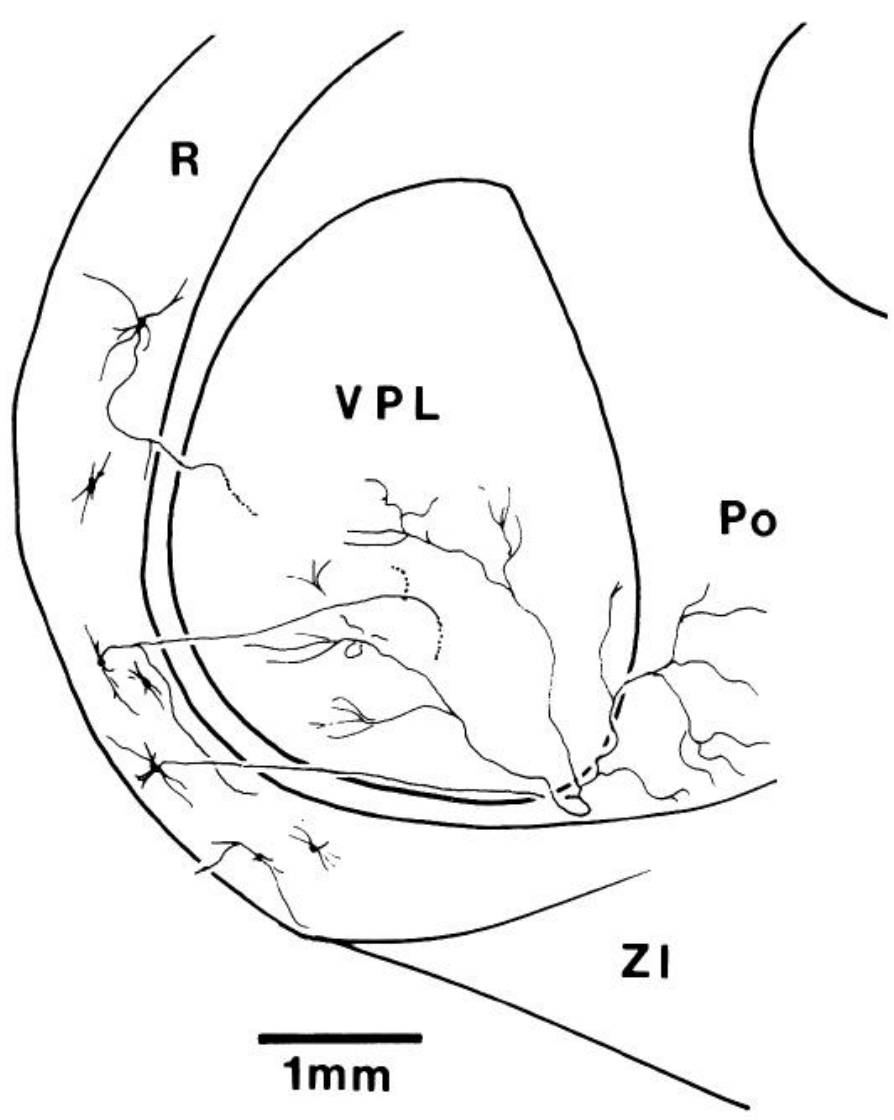

Figure 3. Composite camera lucida drawing from sagittal sections showing the locations of seven of the injected reticular nucleus cells that had somatic sensory receptive fields. $P O$, posterior complex; $R$, reticular nucleus; VPL, ventral posterior lateral nucleus; ZI, zona incerta.

\section{Materials and Methods}

The study is divided into two parts. In the first part, 16 cats weighing 1.9 to $5.8 \mathrm{~kg}$ were used. Animals were anesthetized with sodium pentobarbital,

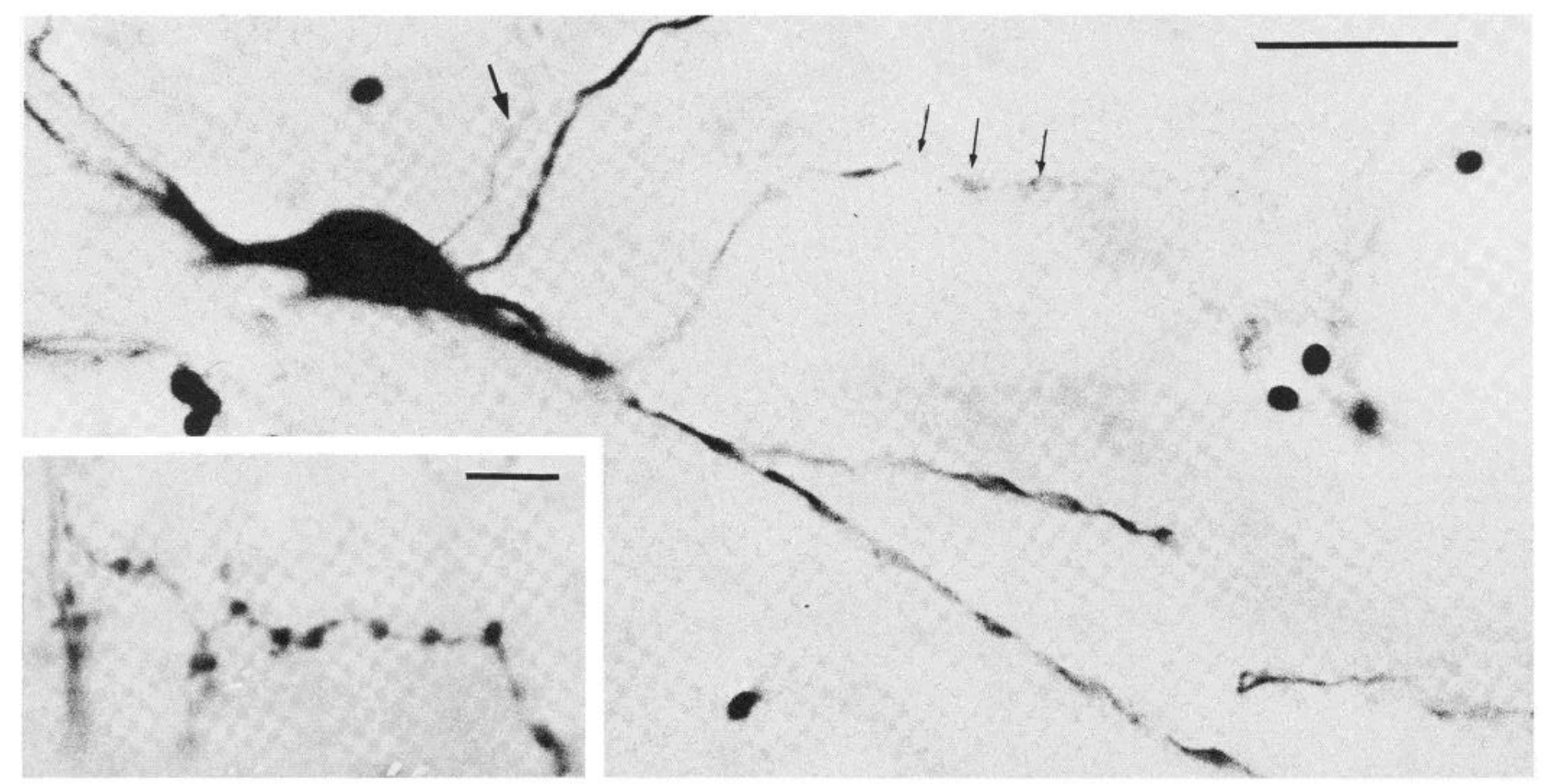

Figure 2. Photomicrograph showing part of an injected neuron in the reticular nucleus in a sagittal section. The large arrow indicates the axon; small arrows indicate beaded dendritic terminals. Bar, $50 \mu \mathrm{m}$. Inset, Photomicrograph of axon terminals of the same cell in the dorsal thalamus. Bar, $10 \mu \mathrm{m}$. 


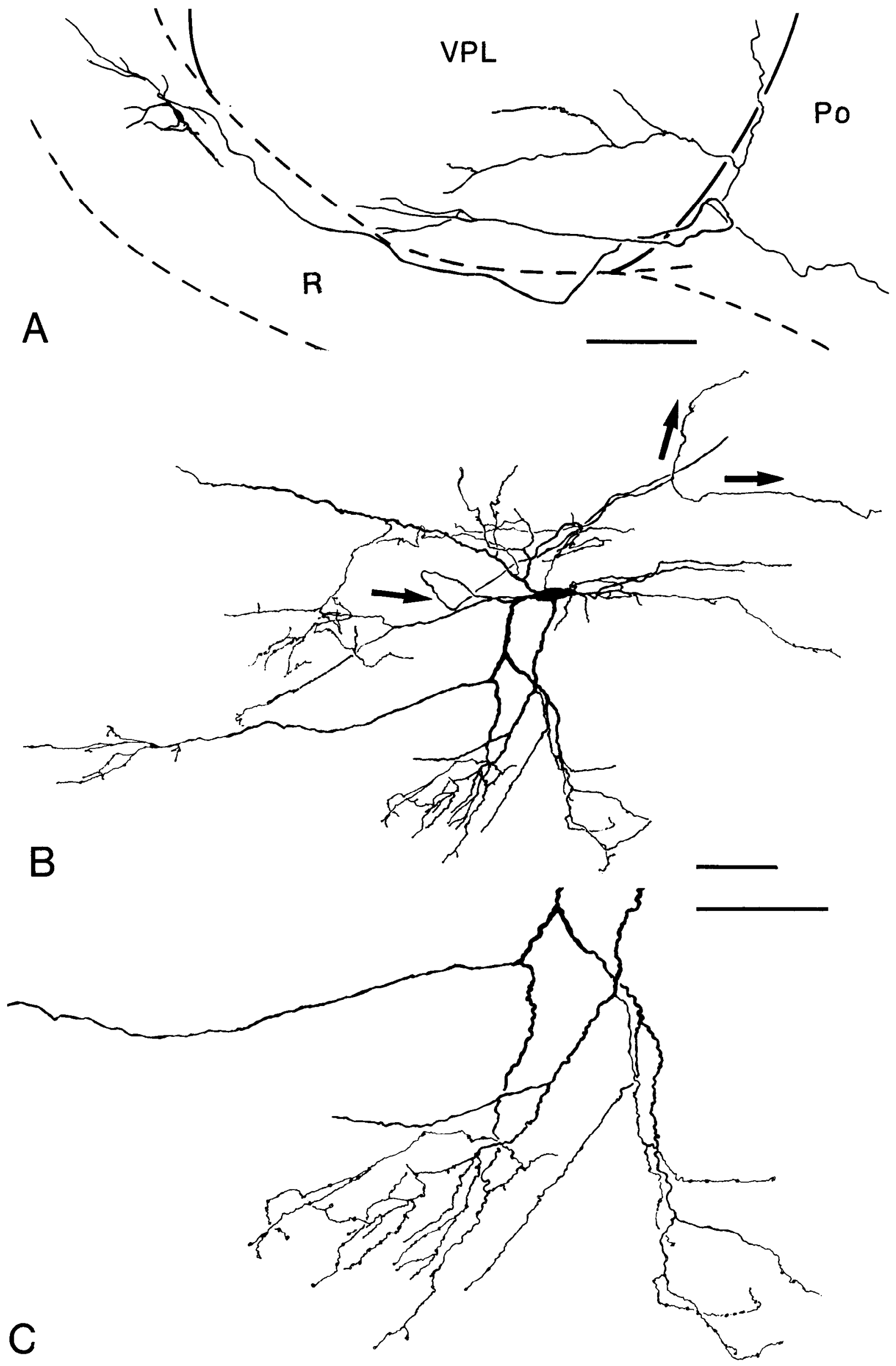

Figure 4 

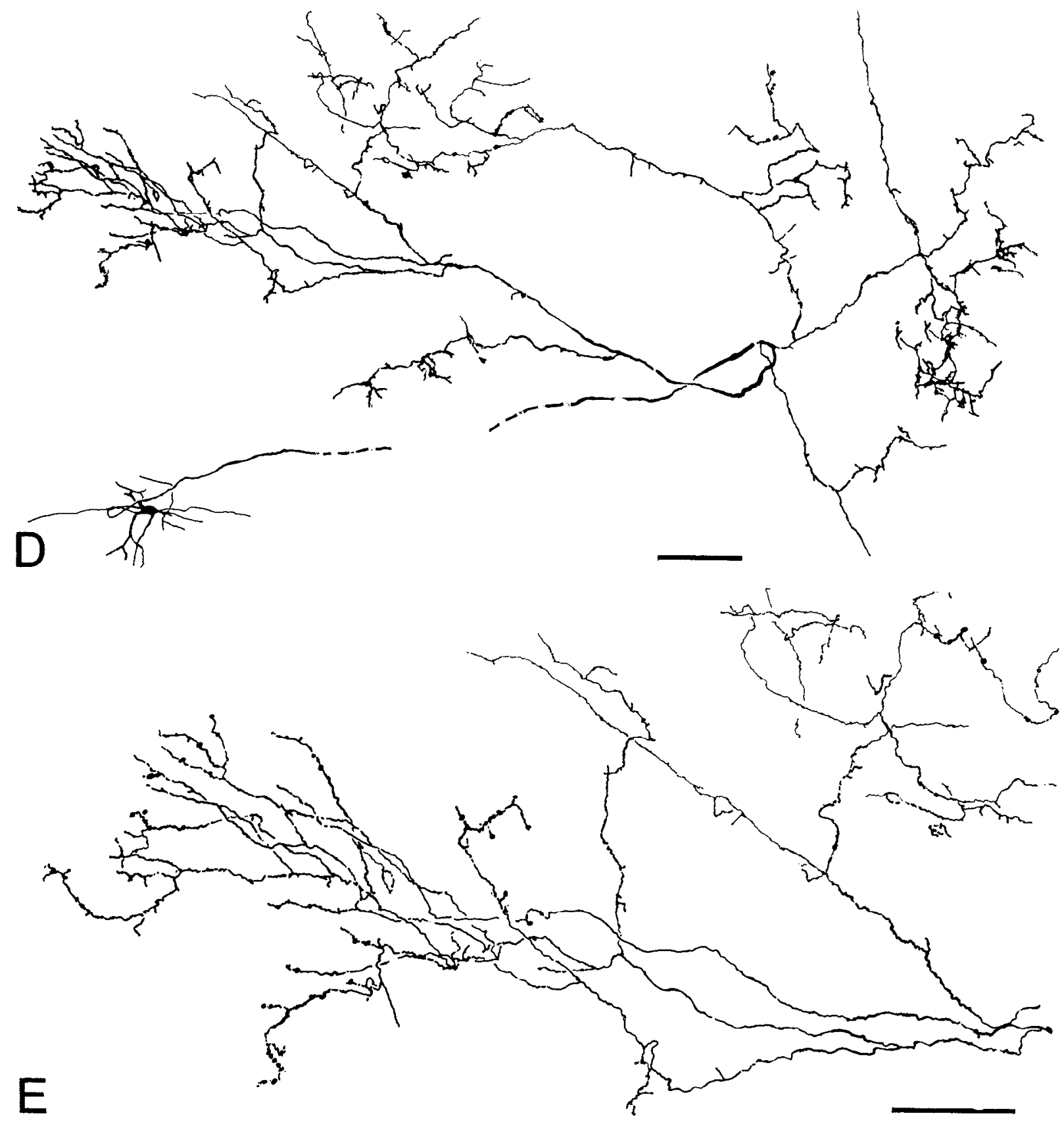

Figure 4. Camera lucida drawings of an injected reticular nucleus cell with a somatic sensory receptive field. Note the entry of the axon into the vontral posterior lateral (VPL) and posterior complex $(P O)$ nuclei in $A$. Dashed lines in $A$ indicate boundaries of reticular nucleus. Sagittal section. In $B$, arrows indicate axon and axon collaterals. Note the axon-like terminals at the ends of dendrites, some of which are drawn at higher magnification in $C$. $D$ shows the extent of the axon, part of which is drawn at higher magnification in $E$. The axon is drawn foreshortened in $D$. Bars, $A$ and $D: 500 \mu \mathrm{m} ; B, C$, and $E$ : 100 $\mu \mathrm{m}$

and a cannula was placed in the femoral vein for the administration of supplemental doses of pentobarbital, a muscle relaxant, and fluids. A second cannula in the femoral artery was used to monitor blood pressure. Body temperature was maintained at approximately $37.5^{\circ} \mathrm{C}$. Silastic cuffs contain ing bipolar silver wire electrodes were placed bilaterally on the intact median and scialic nerves. A varnish-insulated, monopolar tungsten electrode (resistance 100 kilohms) was inserted into the medial lemniscus of one side close to its decussation. Stereotaxic placement of this electrode was guided by recording multiunit activity evoked by electrical stimulation of the median and sciatic nerves. A bipolar cutaneous electrode consisting of a pair of 27 gauge hypodermic needles was available for inserting into the skin for evaluating orthodromic latencies of stimuli applied to a receptive field.

Just before intracellular recordings began, a bilateral pneumothorax was performed, gallamine triethiodide was administered, and thereafter the animal was artificially respired, with end-tidal $\mathrm{CO}_{2}$ being maintained at 3.5 to $4.5 \%$.

The skull was opened over the first somatic sensory area (SI) of the cortex and over a region overlying the thalamus. A bipolar silver ball electrode was placed on the forelimb region of $\mathrm{SI}$, the region being identified by a brief multiunit mapping.

The cortex and hippocampus overlying the thalamus on the same side were removed by gentle aspiration. Then the walls of the cavity were lined with Gelfoam, and a plastic cylinder approximately $1 \mathrm{~cm}$ in diameter was placed on the dorsal surface of the thalamus; all electrode penetrations were made through the unimpeded opening that it provided.

The ventral posterior nucleus of the thalamus was identified in one or more penetrations of a stainless steel microelectrode, unit activity in the nucleus being induced by electrical stimulation of nerves or natural stimulation of the skin. The position of the reticular nucleus lateral to the ventral posterio lateral nucleus was calculated from coordinates determined with the steel microelectrode. Thereafter, glass micropipettes were inserted and aimed at the reticular nucleus.

Glass microelectrodes with internal microfilaments were pulled either on a 
Brown-Flaming horizontal electrode puller or on a Kopf vertical puller and filled with $5 \%$ or $10 \%$ I IRP (Worthington) in $0.1 \mathrm{M}$ Tris buffer and $0.5 \mathrm{M}$ potassium chloride $(\mathrm{pH} 7.3$ to 7.4$)$. DC resistances of the electrodes were 4010200 megohms. These electrodes were lowered into the thalamus using a remote controlled microdrive. After insertion of the electrode into the thalamus, the plastic cylinder was filled with low melting point wax.

Signals were led through the head stage of a Eutectics 400 high voltage electrometer and monitored on storage oscilloscopes and via an audio amplifier and loudspeaker. Permanent records were photographed from the oscilloscope face.

Once a unit was isolated extracellularly, the size and location of its receptive field, if any, were plotted and an effort was made to determine whether it could be activated by electrical stimulation of the SI cortex and/or by electrical stimulation of contralateral or ipsilateral peripheral nerves. The stimuli used were usually single shocks of $20 \mu \mathrm{sec}$ duration and at 1.5 times threshold-usually 0.4 to $0.5 \mathrm{~V}$ for peripheral nerves and 10 to $30 \mathrm{~V}$ for the cortex. The latencies of any responses were recorded and the possibility of antidromic activation from the cortex was explored. Thereafter, an attempt was made to penetrate the unit intracellularly.

After a successful intracellular penetration, indicated by a membrane potential of at least $-40 \mathrm{mV}$, a spike height larger than $30 \mathrm{mV}$, and spontaneous excitatory or inhibitory postsynaptic potentials, the receptive field and latencies of input were quickly confirmed and HRP was injected by iontophoresis. Short, 100-msec bursts of square wave depolarizing current ( 4 to $5 \mathrm{nA}$ ) were passed for 3 to $10 \mathrm{~min}$. Electrode tracks in which HRP was injected were always separated by at least $1 \mathrm{~mm}$.

One hour after the last HRP injection, the animal was perfused through the heart with normal saline followed by a solution of $1 \%$ paraformaldehyde and $2.5 \%$ glutaraldehyde in $0.1 \mathrm{M}$ phosphate buffer $(\mathrm{pH} 7.4)$. Brains were blocked and allowed to sink in $30 \%$ sucrose in phosphate buffer at $4^{\circ} \mathrm{C}$. Fifty-micrometer-thick sagittal sections were cut serially on a freezing microtome, and the whole series was reacted for peroxidase histochemistry using a modified version of the cobalt-enhanced diaminobenzidine technique (Adams, 1977). Every fifth section was counterstained with thionin.

Camera lucida drawings were made of all intracellularly injected cells. Reconstructions of individual cells were made by superimposing camera lucida drawings at progressively increasing magnification $(\times 2.5$ to $\times 1250)$. Because cells were stained in isolation, reconstruction from section to section presented no problems. Sectioned blood vessels served as markers for orienting successive sections.

In the second part of the study, sections of the thalami from three normal cats were stained immunocytochemically for glutamic acid decarboxylase (GAD). The animals were perfused with a mixture of $2 \%$ paraformaldehyde and $0.125 \%$ glutaraldehyde at $\mathrm{pH} 6.4$, followed by the same mixture at $\mathrm{pH}$ 8.4. Frozen sections through the thalamus of two animals were cut at 50 microns thickness while Vibratome sections through the thalamus of the third animal were cut at 40 microns. All sections were stained, free-floating, for GAD immunoreactivity using an anti-GAD antiserum prepared in rabbits (Brandon, 1983) and a double bridge peroxidase-antiperoxidase technique (Hendry et al., 1984), followed by a nickel- and cobalt-enhanced diaminobenzidine method (Adams, 1981). Controls were run by omitting the primary or secondary antiscra from the staining procedure.

The immunocytochemically stained Vibratome sections were mounted under a plastic coverglass in Spurr's resin. The sections were examined, and camera lucida drawings and ptıolographs were made of appropriate parts of the reticular nucleus. Then the coverglass was gently peeled off, and a piece containing the selected part of the reticular nucleus and recognizable blood vessels to be used as landmarks was cut out and glued to a blank block cast from Spurr's resin. Thereafter, thin sections were cut from the surface of the re-embedded section, collected on formvar-coated slot grids, stained lightly with lead citrate, and examined in a Zeiss EM 9S or a Philips EM 300 electron microscope.

\section{Results}

Twenty-six units were studied intracellularly in the somatic sensory part of the reticular nucleus. Of these, eight were recovered histologically after intracellular or intra-axonal injection of HRP. With one exception, all of the units studied had somatic sensory receptive fields. The remaining unit was driven by visual stimuli only and will not be considered further. All injected cells lay within the confines of the reticular nucleus. Noninjected cells could be related to the reticular nucleus by the positions of the electrode tracks along which they were recorded. None of these tracks traversed the dorsal thalamus at the recorded depths at which units were isolated. All of the reticular nucleus units, injected and noninjected, were localized in the part of the nucleus lying immediately anterolateral or anteroventral to the anterior pole of the ventral posterior lateral nucleus.

All of the reticular nucleus units showed the characteristic, spontaneous, bursting behavior that has been demonstrated repeatedly in animals under barbiturate anesthesia (Schlag and Waszak, 1971; Frigyesi and Schwartz, 1972; Steriade and Wyzinski, 1972; Steriade, 1978, 1983). The bursts, each consisting of short-lasting, high frequency discharges were usually imposed upon a fast, irregular pattern of spontaneous discharge.

Receptive fields were large, commonly covering the whole contralateral forelimb or hindlimb, a limb and part of the trunk, the two contralateral limbs, and in two cases, the whole body. The smallest receptive fields were one covering the whole contralateral forepaw and wrist and one covering the whole contralateral hindpaw and ankle.

The types of somesthetic stimuli that were effective in driving the cells were difficult to define. For 20 of the cells, the most effective stimulus was a low frequency (less than $2 \mathrm{~Hz}$ ) tapping of low to medium intensity applied to a body part. Elsewhere we have referred to this type of unit as a T2 unit (Yen et al., 1985). One unit responded to light air puffs that moved hairs and responded transiently to steady light pressure (a hair transient $(\mathrm{Ht})$ unit in our (Yen et al., 1985) scheme). Another responded continuously to steady light pressure and to air puffs (a hair sustained (Hs) unit). One responded to a camel's hair brush lightly stroked across its receptive field (a brush (B) unit). Two other units in the part of the reticular nucleus in which other units were driven by cutaneous or tapping stimuli could not be reliably driven by peripheral stimulation.

Latencies to the first spike induced by electrical stimulation of contralateral receptive fields varied from 16 to $19 \mathrm{msec}$, the shorter latencies being associated with forelimb receptive fields and the longer with hindlimb receptive fields. For forelimb units, latencies to stimulation of the contralateral median nerve ranged from 6.6 to 11 msec (mean, $8.4 \mathrm{msec}$ ). Two units responded to ipsilateral median nerve stimulation, one at $6.8 \mathrm{mscc}$ and the other at $25 \mathrm{mscc}$ latency. For hindlimb units, latencies to stimulation of the contralateral sciatic nerve varied from 13 to $25 \mathrm{msec}$ (mean, $16.5 \mathrm{msec}$ ). None were affected by stimulation of the ipsilateral sciatic nerve. Electrical stimulation of the medial lemniscus led to responses (either spikes or EPSPs only) at latencies varying from 2.3 to $6 \mathrm{msec}$ (mean, 4.0 $\mathrm{msec}$ ). Latencies of response of neurons recorded (see Yen et al., 1985 ) in the ventral posterior lateral nucleus to stimulation of the medial lemniscus ranged from 1.1 to $6.4 \mathrm{msec}$ (mean, $2.9 \mathrm{msec}$ ) for type I cells and 1.6 to $8.0 \mathrm{msec}$ (mean, $4.8 \mathrm{msec}$ ) for type II cclls.

No reticular nucleus units could be antidromically activated by stimulation of the Sl cortex. All except three, however, showed other responses to stimulation of the cortex. A single shock to SI (-ig. 1) usually resulted in a long train of spike discharges with a latency to the onset of an EPSP or to the first spike of 1.4 to $10 \mathrm{msec}$ (mean $3.7 \mathrm{msec}$ ). The responses were judged to be trans-synaptic from their shape, inability to follow $100 \mathrm{~Hz}$ stimuli, and lack of collision with spontaneous spikes. However, we could not determine whether the responses were generated by corticoreticular connections or by antidromic invasion of collaterals of thalamocortical axons in the reticular nucleus. In one instance, the response to cortical stimulation was an IPSP with a latency of $8 \mathrm{msec}$.

None of the cells that were activated by somatic sensory stimuli could be driven by auditory or visual stimuli. The types of stimuli used in testing for multimodal inputs consisted of clicks, whistles, jangling keys, a tuning fork applied to the ear bars, and flashlights shone in the eyes. One cell, the most dorsal one localized, was driven by light flash affecting one or both eyes. It was not driven by somesthetic or auditory stimuli.

All injected cells had a similar morphology (Fig. 2). The soma was fusiform or ovoid with the long axis oriented parallel to the external 

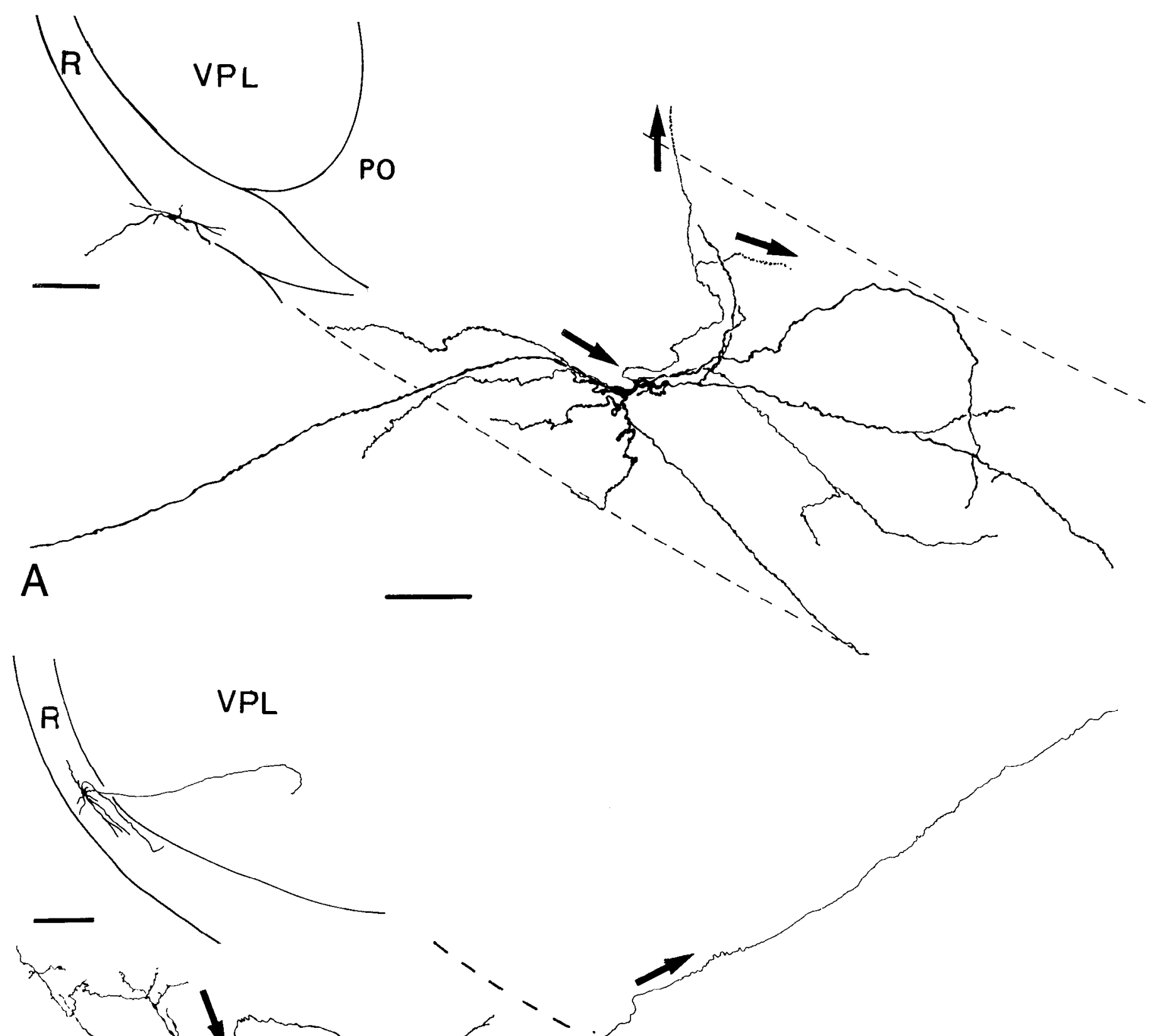

B

Figure 5. Camera lucida drawings of two injected cells $(A, B)$ with somatic sensory receptive fields in the reticular nucleus (see insets), sagittal sections. Arrows indicate the axon, its main trunk entering the ventral posterior lateral nucleus (VPL) and intrareticular collaterals. The cell in $A$ has a dendrite in the internal capsule. Bars, $A$ and $B: 100 \mu \mathrm{m}$; insets: $1 \mathrm{~mm}$ 


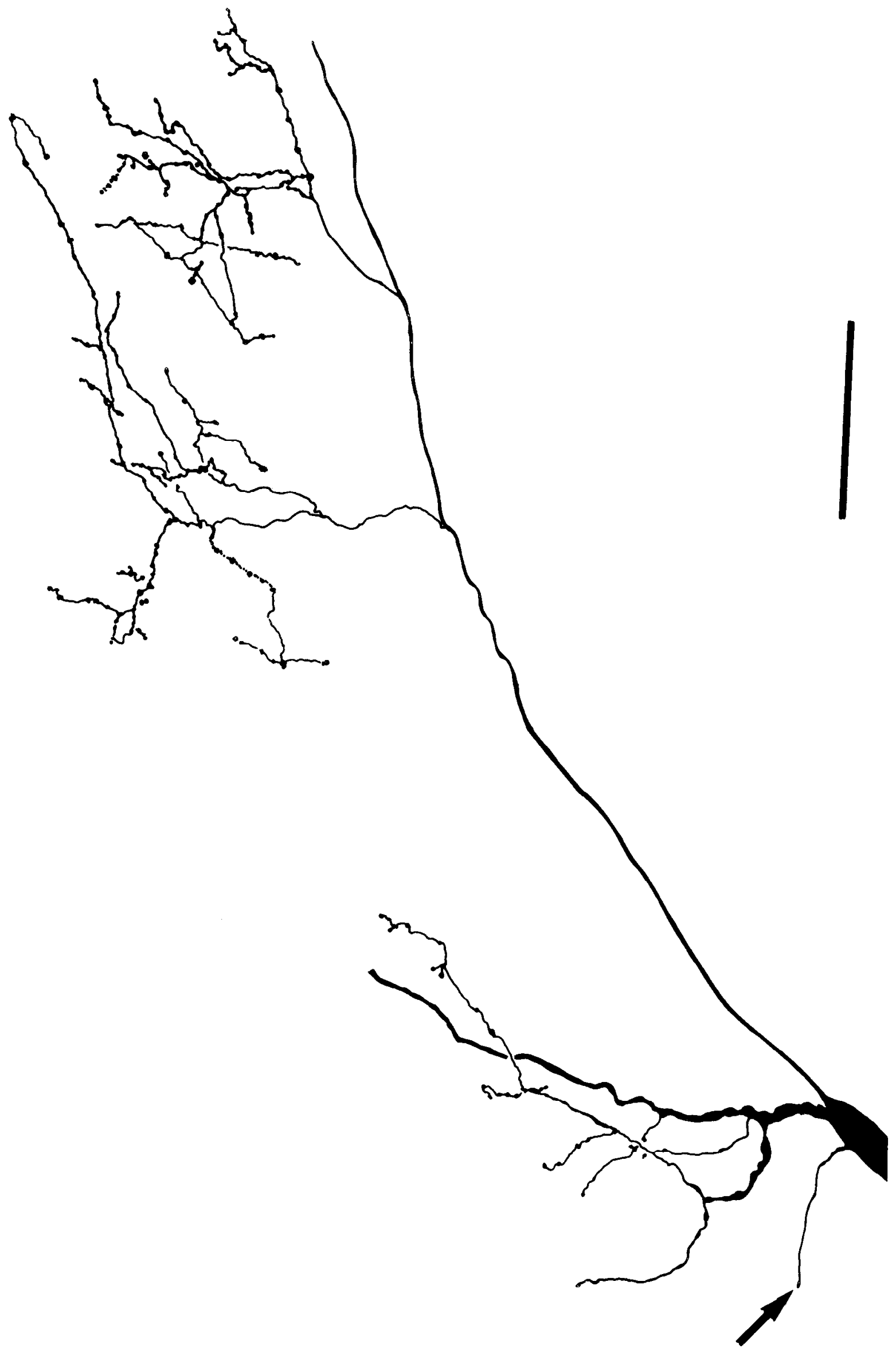



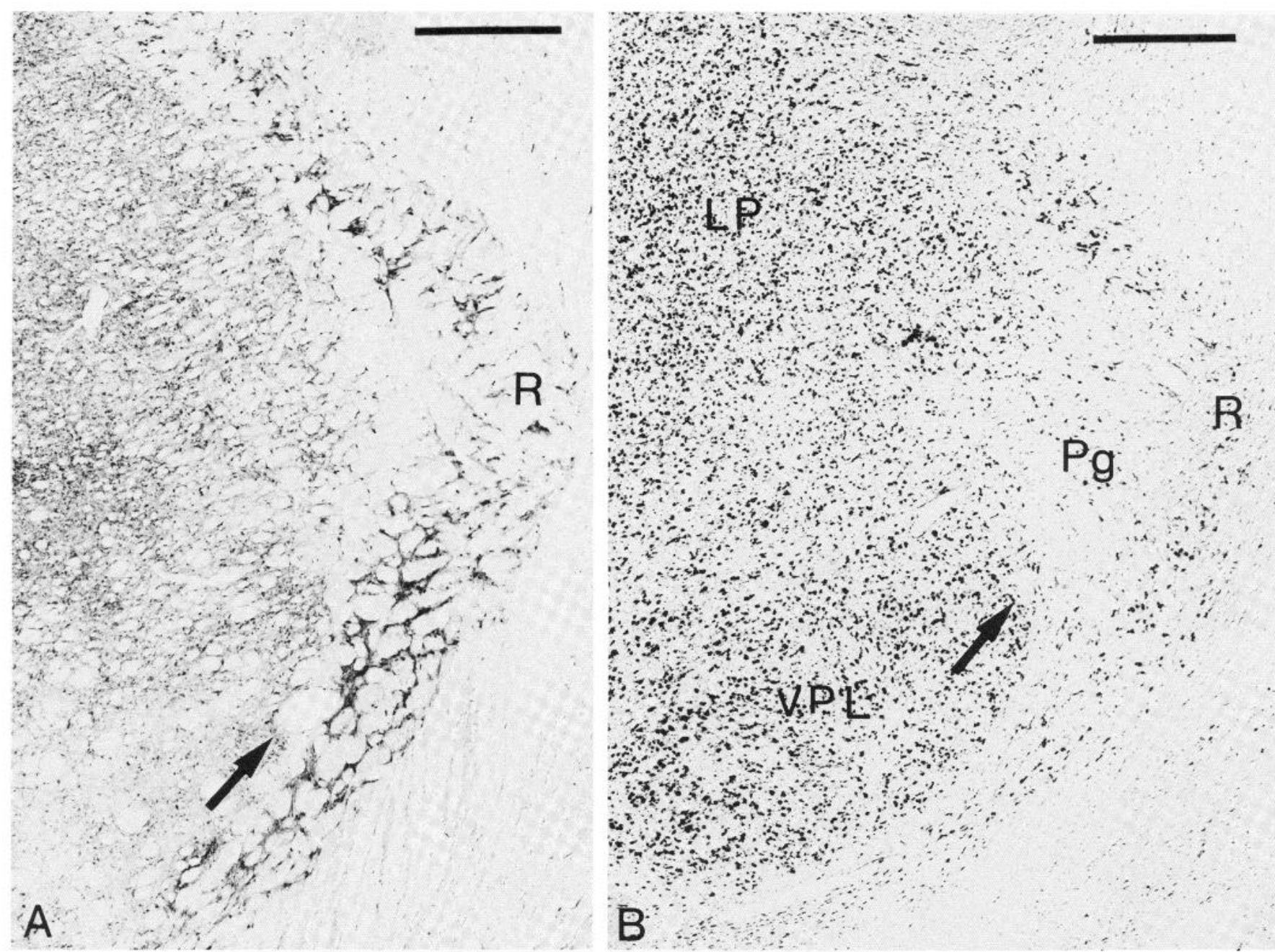

Figure 7. A, Photomicrograph showing GAD immunoreactivity in the reticular nucleus $(R)$ and dorsal thalamus (to the left). Fine dots in dorsal thalamus are GAD-immunoreactive neurons. Uncounterstained frontal section. Bar, $0.75 \mathrm{~mm}$. $B$, Alternate section stained with thionin. The arrow indicates the same blood vessel as in $A$ and in Figure $8 A$. $L P$, lateral posterior nucleus; $P g$, perigeniculate nucleus; VPL, ventral posterior lateral nucleus.

medullary lamina. The soma of the smallest cell measured $24 \times 10$ $\mu \mathrm{m}$; the largest measured $50 \times 10 \mu$. Mean area of the somata of all cells injected was $328.5 \mu \mathrm{m}^{2}$.

Each cell possessed no more than four or five primary dendrites, most of which tended to continue the long axis of the soma parallel to the external medullary lamina (Figs. 2 to 6). Commonly, however, one or two dendrites left the soma at right angles to the others and thus, lay across, rather than in the plane of the thin reticular nucleus. These dendrites occasionally entered the internal capsule lateral to the reticular nucleus (Figs. 3 and 5), but none were seen to enter the dorsal thalamus.

Most of the primary dendrites branched once or twice, the daughter branches commonly continuing the trajectory of the parent branch. Those given off from the occasional primary branches oriented across the reticular nucleus usually turned at right angles to the parent branch and remained within the reticular nucleus. A cell could, thus, have two or more tiers of long dendrites oriented in different parallel planes in the nucleus. Most secondary dendrites terminated in tufts of short, thin, beaded processes which often closely resembled the terminal ramifications of an axon (Fig. 4 to 6).

Very thin axons, less than $3 \mu \mathrm{m}$ in diameter (Fig. 2), arose from the soma or from a proximal dendrite. All of the stained axons curved gently downward and backward to enter the underlying ventral posterior nucleus (Figs. 3 to 5). within the reticular nucleus itself, one or two extremely fine collaterals were given off (Fig. 4). These ran parallel to the surface of the dorsal thalamus for a short distance giving off one or two short, beaded branches and rarely extending outside the limits of the dendritic field of the parent cell, before ending abruptly. All collaterals were stained very faintly and may not have been filled to their ends.

The principal axon trunks, on entering the dorsal thalamus (Fig. 4), broke up into three or four primary branches which ramified through most of the anteroposterior dimension of the ventral posterior lateral nucleus and extended into adjacent parts of the lateral (Pol) and medial (Pom) regions of the posterior nuclear group. The main branches gave rise to sparse plexuses consisting of chains of beaded terminal axons (Fig. $4, D$ and $E$ ) of variable length. The beads were approximately 1 to $2 \mu \mathrm{m}$ in diameter. Some of the plexuses generated by the axon of a single reticular nucleus cell overlapped one another but others were widely separated.

In sections stained immunocytochemically for GAD, cell bodies and proximal portions of primary dendrites of neurons in the reticular nucleus, including the perigeniculate nucleus, were densely stained (Fig. 7). Small, punctate profiles of immunocytochemical reaction product lay around and between the somata and, commonly, parallel chains of such puncta continued the trajectory of one axis of an immunocytochemically stained soma, as though following a proximal dendrite (Fig. 8). The immunocytochemically stained somata measured, on average, $30 \times 10 \mu \mathrm{m}$. No small neurons were stained in the reticular nucleus, although many GAD-stained somata measuring 5 to $10 \mu \mathrm{m}$ in diameter were visible in all of the dorsal thalamic nuclei (Fig. 7A). GAD-stained somata in the part of the reticular nucleus 


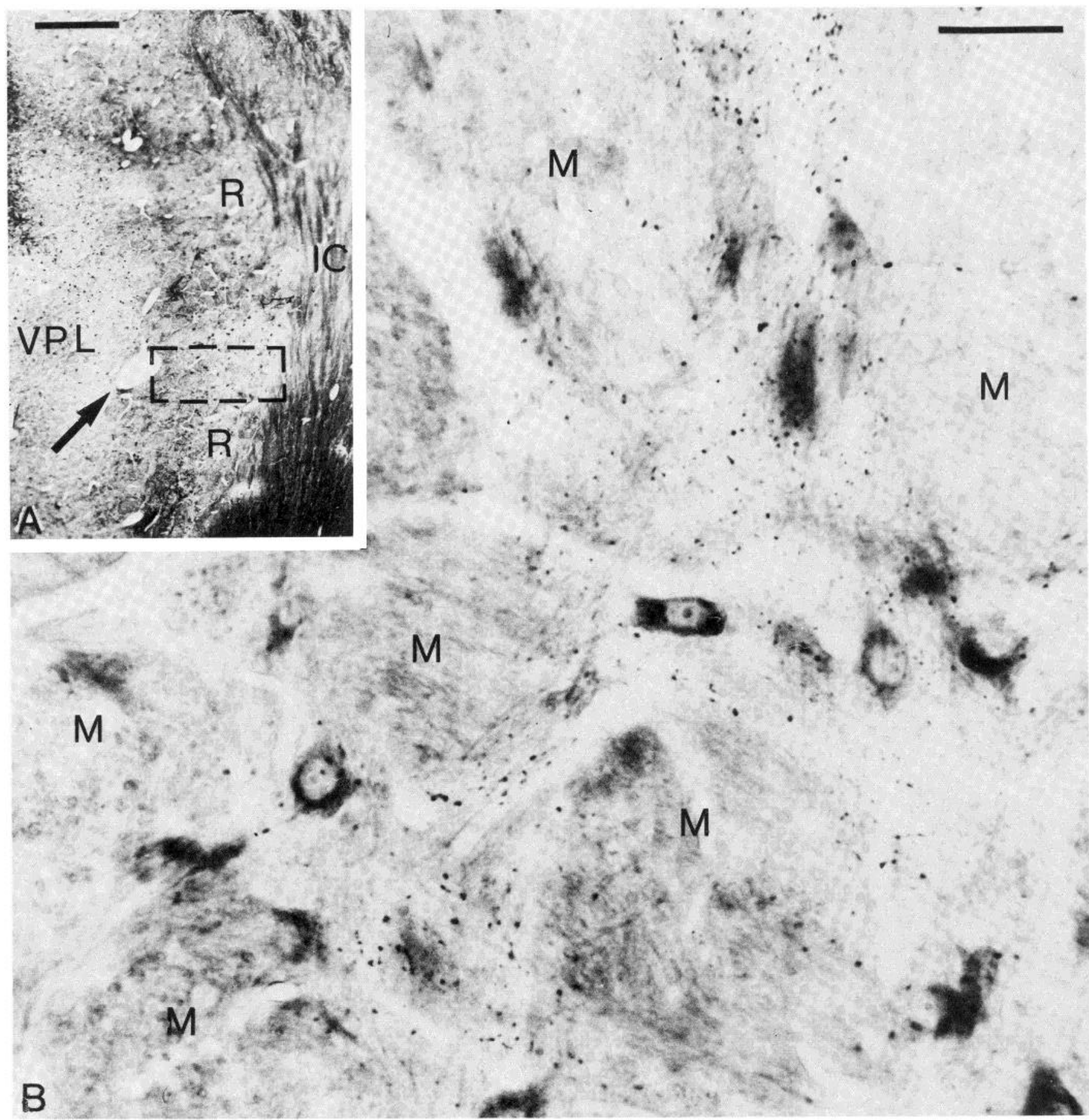

Figure 8. Photomicrographs from Vibratome section adjacent to those in Figure 7, $A$ and $B$, showing the part of the reticular nucleus lying ventrolateral to the ventral posterior lateral nucleus (VPL) and immunoreactive for GAD. The rectangle in $A$ shows the region reimbedded for electron microscopy. The arrow indicates the same blood vessel as in Figure 7, $A$ and $B . B$ shows GAD-immunoreactive cells and puncta in the rectangle in $A$ at higher magnification. Large, background-stained, round profiles $(M)$ are bundles of external medullary lamina between which puncta and cells lie. Bars, $A: 500 \mu \mathrm{m} ; B: 100 \mu \mathrm{m}$. IC, internal capsule.

Figure 9. Electron micrographs from the rectangular region in Figure $8 A$, showing (inset to $A$ ) large $(L)$ and small $(S)$ immunoreactive profiles interpreted as presynaptic dendrites and terminals of intranuclear axon collaterals, respectively, of reticular nucleus neurons. $A$, Immunoreactive dilatation of a dendritic process (arrows) terminating (arrowhead) on a dendrite $(D)$ which was also immunoreactive. $B$, Two immunoreactive dendrites $(D)$ one of which (arrows) shows a localized aggregation of synaptic vesicles and increased immunoreactivity. $M$, immunoreactive myelinated axon. $C$, Two weakly immunoreactive dendrites $(D)$ receiving (arrows) terminations from immunoreactive, synaptic vesicle-filled profiles. Two nonimmunoreactive axon terminals $(N)$ are making synaptic contacts (small arrows) on weakly GAD-immunoreactive dendrites. $D$, Vesicle-filled, GAD-immunoreactive profile making synaptic contact (arrows) on an immunoreactive dendrite $(D)$. In all of the electron micrographs the differences in density of immunoreactive material seen in dendrites or somata and vesicle-filled profiles are typical of our material. Bars, inset, $A$, and $B: 1 \mu \mathrm{m} ; C$ and D: $0.5 \mu \mathrm{m}$. 

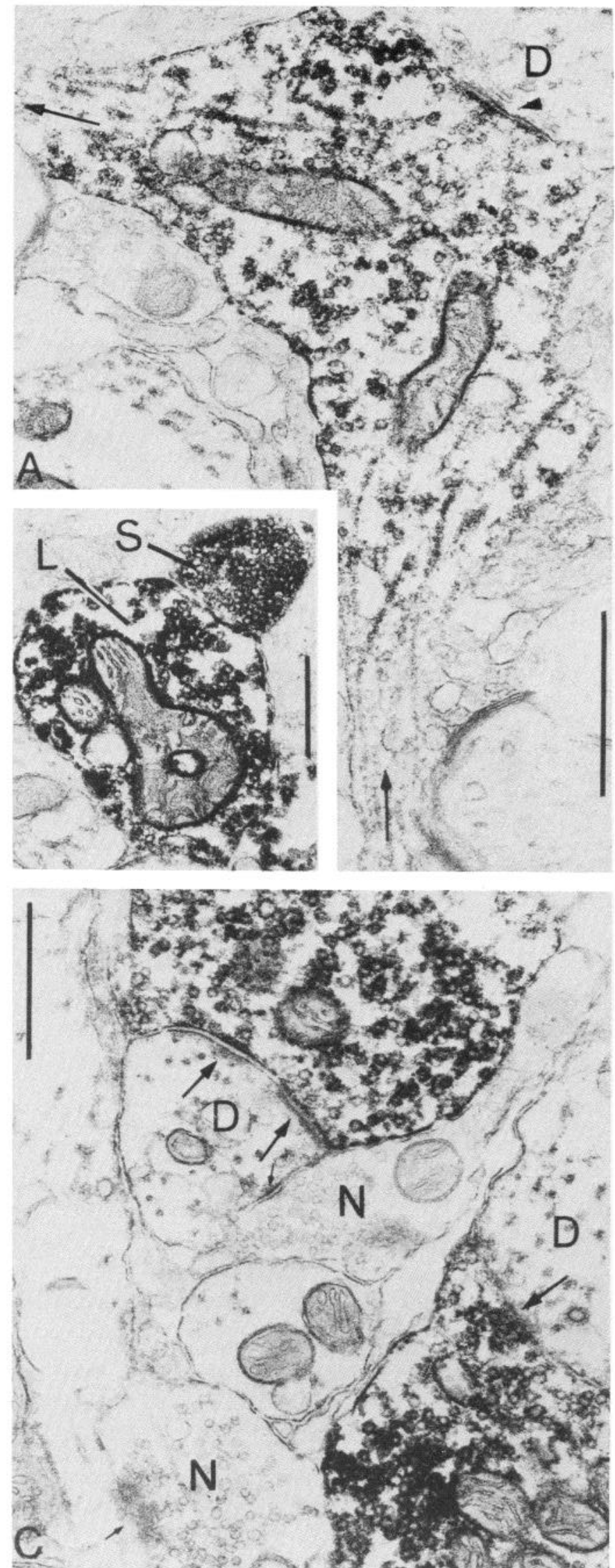
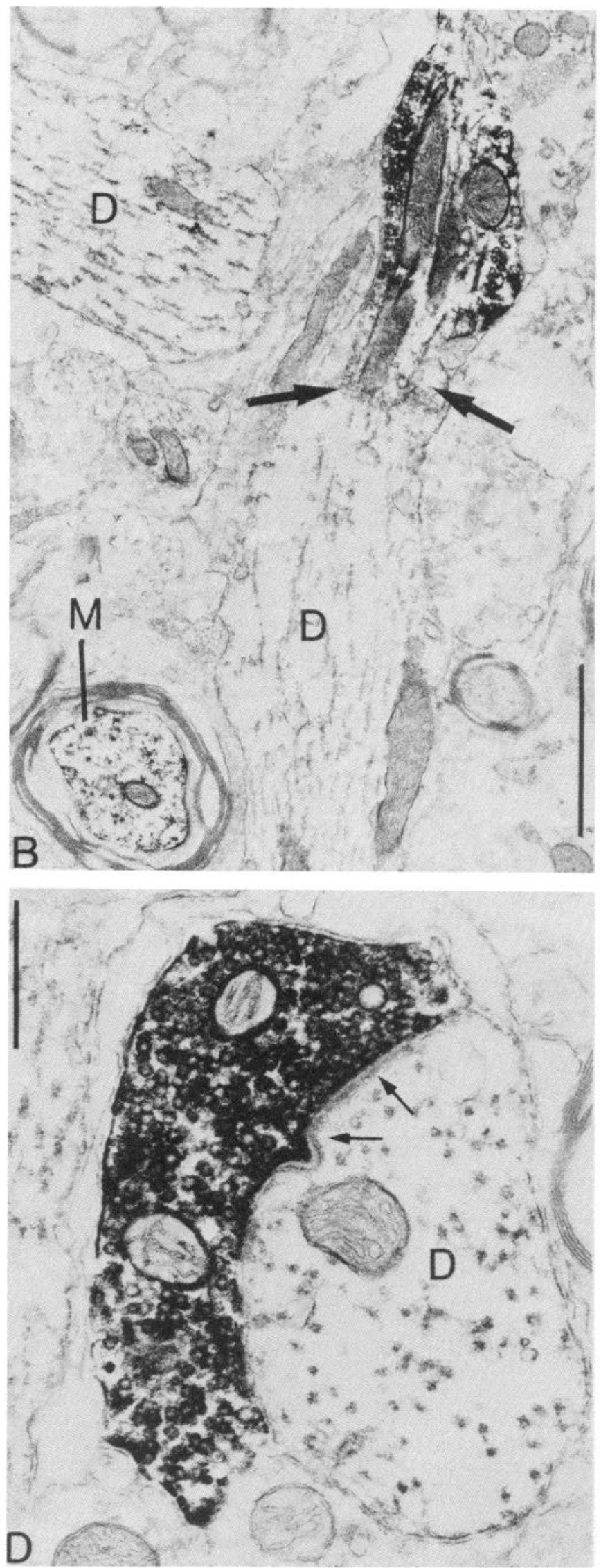
lying anterolateral and anteroventral to the ventral posterior nucleus were counted in rectangles approximately $1 \mathrm{~mm}^{2}$ in area and outlined by an eyepiece reticule in the microscope. The number of GADpositive cells in 10 counts varied from 65 to 75 (mean, 69). Nisslstained sections immediately adjacent to the GAD-stained sections were then used to count the number of neuronal somata in a $1-\mathrm{mm}^{2}$ area serial to that in which GAD-stained somata were counted (see, Fig. 8). Blood vessels served as markers to align the eyepiece reticule over the same part of the reticular nucleus in each pair of GAD-and Nissl-stained sections. Counts of somata stained in the Nissl sections were virtually identical to those counted in the GAD sections; the difference was never greater than $10 \%$, and in 7 of the 10 counts the number of cells differed by only one or two.

Electron microscopic examination of blocks containing immunocytochemically stained somata and punctate profiles revealed comparable profiles. No additional unstained cell somata could be detected in sections close to the surfaces of the blocks, although most sectioned somata and dendrites contained far less reaction product than did immunoreactive terminals. Immunocytochemically stained profiles of the same size as, and presumably equivalent to, the puncta of light microscopy were revealed as sections of large GAD-positive profiles containing moderate populations of synaptic vesicles (Fig. 9). Some of the less heavily stained profiles of this type contained readily identifiable rosettes of ribosomes and small fragments of rough surfaccd cndoplasmic reticulum. Many were seen in continuity with large dendrites (Fig. 9). Other, smaller profiles were tightly packed with synaptic vesicles, and no other organelles except occasional mitochondria could be seen (Fig. 10). Both sets of vesicle-containing, immunoreactive profiles made synaptic contacts on immunoreactive dendrites or cell somata and, occasionally, the smaller profiles were also presynaptic to the larger (Figs. 9 and 10). Where clearly identifiable, the contacts were symmetric, but reaction product often made identification difficult. Large and small terminals making asymmetric synapses were readily identified (Figs. $9 C$ and $10 A, B$, and $D$ ), but none were seen to be immunoreactive. Apart from these profiles forming asymmetric synapses, every block invariably contained a population of large, vesicle-containing profiles that never contained ribosomes, invariably made symmetric synaptic contacts, and showed no immunoreactivity even when other, similar profiles adjacent to them were heavily immunoreactive for GAD.

\section{Discussion}

The part of the reticular nucleus sampled in this study is clearly dominated by the somatic sensory system. Only one unit in our sample responded to nonsomesthetic stimuli, and it was situated dorsal to the remainder of the units that were isolated.

Other workers have reported comparable somatic sensory parts of the reticular nucleus in rats (Sugitani, 1979; Shosaku et al., 1984), cats, and monkeys (Pollin and Rokyta, 1982); in other portions of the nucleus, units are driven selectively by visual (Sanderson, 1971; Sumitomo et al., 1976; Ahisén and Lindström, 1982a, b; Hale et al., 1982) or auditory (Shosaku and Sumitomo, 1983) stimuli. A parcellation of the nucleus in relation to the main afferent systems of the forebrain was to be expected, on account of the clear demonstration that thalamocortical fibers en route to the cortex from the somatic sensory, visual, and auditory relay nuclei of the thalamus traverse a particular sector of the reticular nucleus and give rise to terminals within that portion (Jones, 1975; Montero et al., 1971). In the cat and other carnivores the visual part of the reticular nucleus is the perigeniculate nucleus (Jones, 1985) and, in both it and the somatic sensory part of the reticular nucleus, collateral branches of the traversing thalamocortical axons have been directly visualized by intracellular injection of HRP (Ahlsén et al., 1978; Friedlander et al., 1979, 1981; Stanford et al., 1983; Yen and Jones, 1983; Yen et al., 1985).

We obtained no evidence to indicate direct inputs to the reticular nucleus from the medial lemniscus or any other peripheral somesthetic pathway. The fastest inputs to the reticular nucleus cells were always 1 to $2 \mathrm{msec}$ delayed in comparison with the fastest inputs to neurons of the ventral posterior nucleus. We assume, therefore, that the principal afferent drive to the somatic sensory part of the reticular nucleus is via collaterals of thalamocortical axons arising in the ventral posterior nucleus and passing through this part of the reticular nucleus en route to the somatic sensory cortex. Direct inputs from the optic tract to the perigeniculate nucleus of the cat had unce been postulated because of the short latency of response to optic tract stimulation (Schmielau, 1979). This suggestion now seems to be discounted by observations in the somatic sensory, auditory, and visual parts of the reticular nucleus. These indicate, as does the present study, that reticular nucleus neurons are excited by peripheral stimulation at latencies sufficiently longer than those of relay cells in the corresponding nucleus, to imply one synaptic delay (Sugitani, 1979; Ahlsén and Lindström, 1982a; Hale et al., 1982; Pollin and Rokyta, 1982). In the perigeniculate nucleus, Ahlsén and Lindström (1982a) have been able to show collision of excitatory potentials having disynaptic latencies due to optic tract stimulation with those having monosynaptic latencies due to antidromic stimulation of thalamocortical axons and, thence, of their collaterals in the perigeniculate nucleus.

Another type of input to the reticular nucleus is composed of prosumed collaterals of corticothalamic fibers. The corticothalamic inputs have been demonstrated by light and electron microscopic anatomical techniques (Jones, 1975; Ohara and Lieberman, 1981), and our evidence for orthodromic synaptic activation of reticular nucleus cells by cortical stimulation may confirm this. However, we could not rule out that some of the responses was saw on stimulating the cortex were due to antidromic invasion of thalamocortical relay cell axon collaterals terminating in the reticular nucleus. The latter explanation has been advanced in the perigeniculate nucleus by Lindström (1982) who feels that corticoreticular fibers from the visual cortex are less likely to activate perigeniculate cells at latencies as short as we found.

Corticothalamic axons destined for a particular dorsal thalamic nucleus traverse the same part of the reticular nucleus as thalamocortical fibers arising in the dorsal thalamic nucleus and targeted on the cortical area(s) from which the returning corticothalamic fibers arise. This tight interrelationship between thalamocortical and corticothalamic fibers seems to ensure that a single part of the reticular nucleus will be dominated by one modality. Montero et al. (1977) have reported, in an anatomical study, the presence of a retinotopic map in the visual part of the reticular nucleus, and Pollin and Rokyta (1982) and Shosaku et al. (1984), in physiological studies, have reported a somatotopic map in the part through which fibers from the ventral posterior nucleus pass en route to the somatic sensory cortex. No clear somatotopy could be identified in the present study, although units with receptive fields on different parts of the body were identified.

It would not be surprising if a body somatotopy comes to be recognized in the part of the reticular nucleus that we sampled. Thalamocortical fibers leaving the somatotopically organized ventral posterior nucleus and destined for the somatotopically organized somatic sensory cortex would be expected to preserve the soma-

Figure 10. Electron micrographs from the rectangular region in Figure 8A. A. Three vesicle-filled immunoreactive profiles, one of which (upper arrows) is

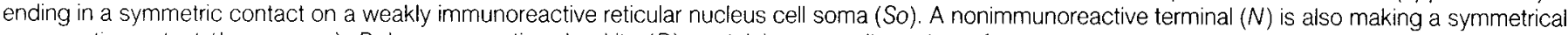

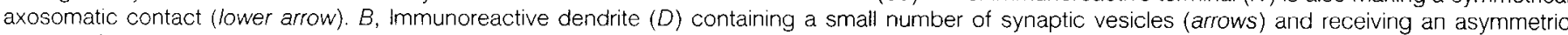
synapse from a nonimmunoreactive terminal $(N)$. C, Immunoreactive dendrite $(D)$ containing a localized region of denser immunoreactive staining (large

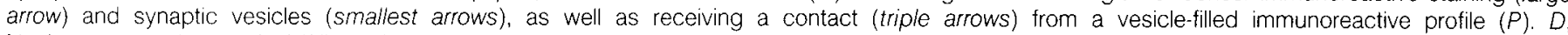
Nonimmunoreactive terminal $(N)$ making an asymmetric synaptic contact on a vesicle-filled immunoreactive proflle $(P)$. Bars, $A: 1 \mu \mathrm{m} ; B$ to $D: 0.5 \mu \mathrm{m}$. 


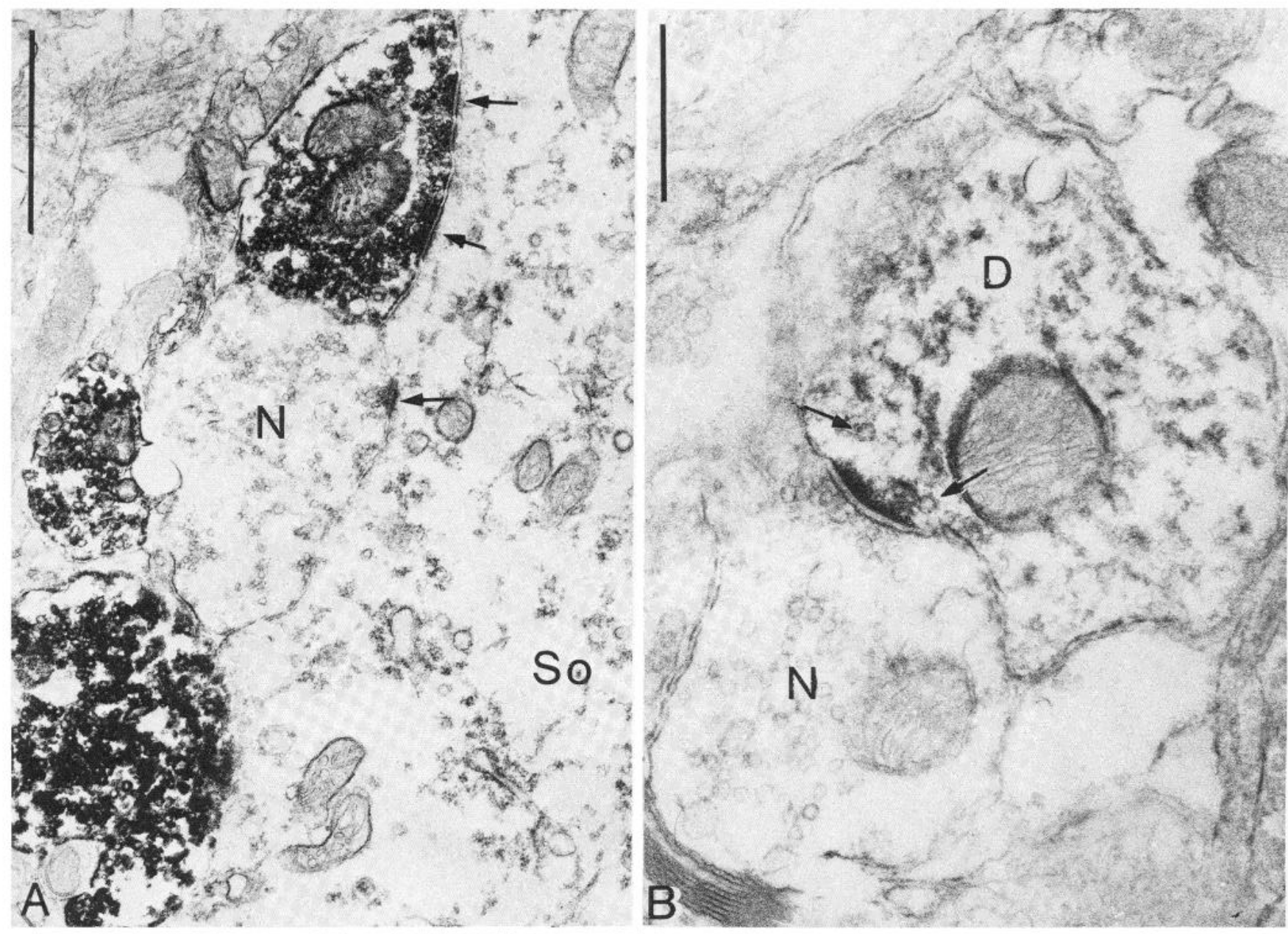

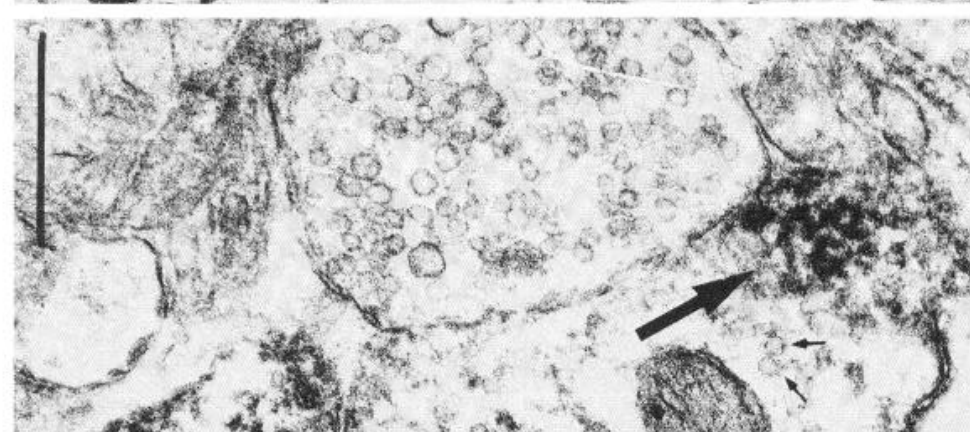
6. $x^{3}+1$ 4.5 4 .

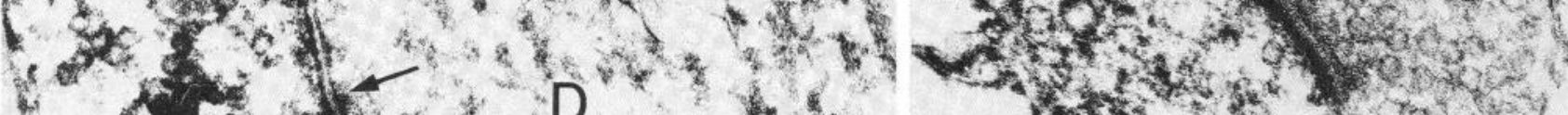

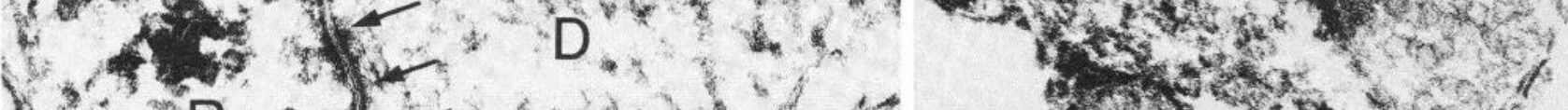

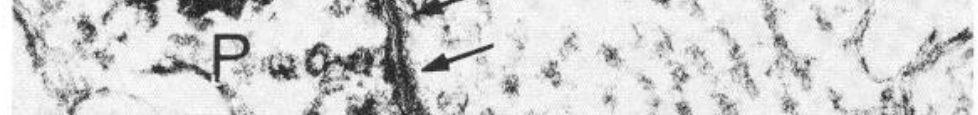
$5 \times 2 .+2$ $\frac{12}{10}$ i.

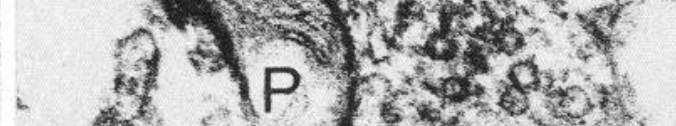

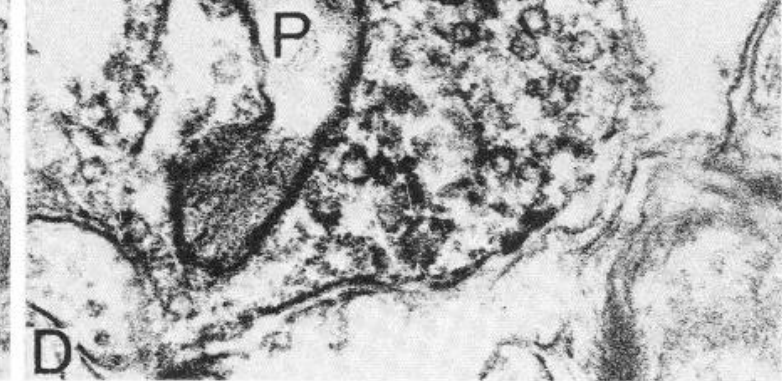


totopy of the nucleus in their relationships to adjacent fibers as they traverse the reticular nucleus. It seems doubtful to us, however, that a fine grain somatotopy could be preserved in the reticular nucleus in regard to any sensory system. In our intracellularly stained neurons we have confirmed the large size and very elongated dendrites of the reticular nucleus cells previously demonstrated in Golgi preparations (Kölliker, 1896; Ramón y Cajal, 1911; Scheibel and Scheibel, 1966). The long dendrites of these cells are oriented in a manner that would make it possible for a single cell to receive synaptic inputs from thalamocortical fibers emanating from widely separated parts of the ventral posterior nucleus, containing neurons with topographically dysjunctive receptive fields. The length of the dendrites of reticular nucleus cells and their orientation in the plane of the reticular nucleus predispose them to innervation from many parts of a single thalamic nucleus and even from more than one nucleus. The former doubtless accounts for the particularly large size of most of the somatic sensory receptive fields recorded in the reticular nucleus in our study and in those of Pollin and Rokyta (1982) and Shosaku et al. (1984), although the origins of the ipsilateral fields found in our study and that of Pollin and Rokyta (1982) are unclear. The inputs from more than one nucleus probably account for the observations of Shosaku and Sumitomo (1983), who demonstrated reticular nucleus units with mixed auditory and somesthetic, or mixed auditory and visual inputs at the borders of the part of the cat reticular nucleus containing auditory units. Evidently, here, the reticular nucleus cells with mixed properties extend dendrites into parts of the nucleus traversed by fibers from both the lateral and modial geniculate nuclei.

The nature of the natural stimuli required to drive units in the somatic sensory part of the reticular nucleus was not well defined. Units clearly responded at short latency to electrical stimulation of the medial lomniscus and of peripheral nerves, but the most effective natural stimulus was a rather crude tapping of a limb or of the trunk. Very few units responded preferentially to light stroking of the skin or movement of hairs. It is likely that the ill-defined nature of the effective stimulus results from convergence of axons arising from ventral posterior nucleus cells with a variety of submodality properties onto single reticular nucleus cells. A similar type of convergence appears to occur in the visual part of the reticular nucleus in which units with "on-off center" receptive fields have been described. These fields must imply convergence of inputs from lateral geniculate neurons with on-center and off-center receptive fields, for on-off center fields are not found in the lateral geniculate nucleus in adult cats (Cleland et al., 1971; Dubin and Cleland, 1977; Daniels et al., 1978; So and Shapley, 1981; Hale et al., 1982). It is interesting to note that units in the ventral posterior nucleus which could not be antidromically activated from the cerebral cortex and some of those which were subsequently shown to be dorsal thalamic interneurons had much smaller receptive fields than did reticular nucleus cells (Yen et al., 1985). This would seem to imply that the dorsal thalamic interneurons, which are also known to be GAD positive (Hendrickson et al., 1983; Ohara et al., 1983; Penny et al., 1983; Spreafico el al., 1983) are subject to far less convergence than is this second group of thalamic GABAergic neurons in the reticular nucleus.

The ramifications of the axons of reticular nucleus cells are quite similar to those previously described in Golgi studies (Ramón y Cajal, 1911; Scheibel arıd Scheibel, 1966) or inferred from autoradiographic experiments (Jones, 1975). The principal axonal trunk of a reticular nucleus cell ramifies quite widely in the dorsal thalamic nucleus (in this case the ventral posterior lateral nucleus) to which the sector of the reticular nucleus containing the cell is functionally related. Within the dorsal thalamic nucleus there is no obvious indication that the ramifications of the axon of a single reticular nucleus cell are limited to regions likely to correspond to the representation of a small body part. This fact and the extension of the ramifications into adjacent parts of the posterior nuclear group (one of which, Pol, appears auditory in its connectional relationships; Jones, 1985) seem to argue against a precise interrelationship based upon tight coupling of topographic representations.

The terminal boutons of reticular nucleus axons in the dorsal thalamus are known to contain flattened synaptic vesicles and to make symmetric synaptic contacts on proximal dendrites of relay neurons and probably on the dendrites of interneurons as well (Ohara et al., 1980; Montero and Scott, 1981; Montero, 1983) Because, from the work of Oertel et al. (1983), Hendrickson et al. (1983), and the present study, every reticular nucleus cell is immunoreactive for $\mathrm{GAD}$, it is to be assumed that the effect exerted by the reticular nucleus cells over cells in the dorsal thalamus is inhibition.

Recent studies of inhibitory phenomena among dorsal thalamic relay neurons have provided strong evidence for an inhibitory effect of some kind being exerted by the reticular nucleus. I he postexcitatory depression that supervenes following relay cell excitation is said to recover more quickly following disconnection of the reticular nucleus from the dorsal lateral geniculate nucleus in the rat (Sumitomo et al., 1976); inhibitory phenomena are difficult to record in slices of the rat dorsal lateral geniculate nucleus from which the reticular nucleus is lacking (Kelly et al., 1979). Single-shock stimulation of the reticular nucleus can suppress spontaneous and evoken activity in the rat dorsal lateral and medial geniculate nuclei (Sumitomo et al., 1976; Shosaku and Sumitomo, 1983); electrical stimulation of the optic tract within the time of postexcitatory depression of thalamocortical relay cells due to a previous stimulus, fails to excite the relay cells or cells in the appropriate part of the reticular nucleus (Hale et al., 1982). IPSPS occurring in relay cells of the cat dorsal lateral geniculate nucleus after electrical stimulation of the visual cortex occur 0.7 to $0.8 \mathrm{msec}$ after EPSPs engendered in perigeniculate cells and are best interpreted as being due to inputs from inhibitory interneurons in the perigeniculate part of the reticular nucleus which were activated following antidromic activation of axons of thalamocortical relay cells, with invasion of their collaterals in the reticular nucleus (Ahlsén and Lindström, 1982a; Lindström, 1982). The development of the geniculate IPSPs with several ripples seems to correspond to repetitive firing of the perigeniculate cells.

The synaptology in the reticular nucleus itself is little known, the only concerted electron microscopic study having been made on the cat perigeniculate nuclcus by ide (1982). If this work can be taken to be representative of the reticular nucleus as a whole, then one population of neurons is present with axon terminal profiles that probably represent the terminations of collaterals of corticothalamic (Ohara and Lieberman, 1981) and thalamocortical axons. These would appear to correspond to the two types of unlabeled torminal profiles making asymmetrical synapses in our material. A third set of axon terminals noted by lde (1982) may represent those of axons arising in the midbrain reticular formation (Edwards and DeOlmos, 1976; Berman, 1977). (The latter are thought to be cholinergic: see Dingledine and Kelly, 1977; Dolabela di Lima and Singer, 1981; Jones, 1985). The terminals of the local collaterals of reticular nucleus axons have not been positively identified electron microscopically but may correspond to isolated GAD-positive terminals seen in our study and in that of Montero and Singer (1984) on the perigeniculate nucleus. The GABAergic nature of the reticular nucleus cells, as revealed by immunocytochemistry, suggests that the collaterals should exert an inhibitory effect within the reticular nucleus and that this may be reflected in the one occasion on which we observed a relatively short-latency IPSP in a reticular nucleus cell following stimulation of the SI cortex. The role of somatostatin found in reticular nucleus cells (Graybiel and Elde, 1983) has not been explored physiologically.

Another form of coupling between reticular nucleus cells is suggested by the presence of presynaptic dendrites described electron microscopically by Ide (1982) and by Montero and Singer (1984) in the perigeniculate nucleus and confirmed by ourselves as being GAD positive and occurring between dendrites of reticular nucleus cells. Our study and those of Hendrickson et al. (1983) and Oertel 
et al. (1983) indicate that every reticular nucleus cell is GAD positive. Therefore, in the absence of a sccond, non-GAD-immunoreactive population of reticular nucleus cells, it seems likely that the presynaptic dendrites occur between reticular nucleus cells that project into the dorsal thalamus. It seems probable that the axon-like terminations seen light microscopically at the ends of the dendrites of our injected cells are these GAD-positive presynaptic elements. Little is known about the functional significance of presynaptic dendrites, even in the dorsal thalamus where they are common and also arise from GABAergic interneurons (Hendrickson, 1983; Ohara et al., 1983; Spreafico et al., 1983; Jones, 1985). It would seem evident, however, that their presence reflects a close coupling between reticular nucleus cells and might account for the mutual inhibition observed between neurons in the perigeniculate nucleus by Ahlsén and Lindström (1982b). Coupling between adjacent large cells would seem to be an additional feature implying a lack of topographic precision in the reticular nucleus and would seem to be an essential prerequisite of Crick's (1984) hypothesis of the function of the reticular nucleus in selective attention.

\section{References}

Adams, J. (1977) Technical considerations on the use of horseradish peroxidase as a neuronal marker. Neuroscience 2: 141-149.

Adams, J. C. (1981) Heavy metal intensification of DAB based HRP reaction product. J. Histochem. Cytochem 29: 775

Ahlsén, G., and S. Lindström (1982a) Excitation of perigeniculate neurons via axon collaterals of principal cells. Brain Res: 236: 477-481.

Ahlsèn, G., and S. Lindström (1982b) Mutual inhibition between perigeniculate neurones. Brain Res. 236: 482-486.

Ahlsén, G., S. Lindström, and E. Sybriska (1978) Subcortical axon collaterals of principal cells in the lateral geniculate body of the cat. Brain Res. 156: 106-109

Berman, N. (1977) Connections of the pretectum in the cat. J. Comp. Neurol. 174: $227-254$.

Brandon, C. (1983) Retinal GABA neurons: Immunocytochemical localization using a new antiserum against rabbit brain glutamate decarboxylase. Soc. Neurosci. Abstr. 9: 800.

Carman, J. B., W. M. Cowan, and T. P. S. Powell (1964) Cortical connexions of the thalamic reticular nucleus. J. Anat. 98: 587-598.

Cleland, B. G., M. W. Dubin, and W. R. Levick (1971) Sustained and transient neurones in the cat's retina and lateral geniculate nucleus. J. Physiol. (Lond.) 217: 473-496

Chow, K. L. (1952) Regional degeneration of the thalamic reticular nucleus following cortical ablations in monkeys. J. Comp. Neurol. 97: 37-60.

Crick, F. (1984) Functions of the thalamic reticular complex: The searchlight hypothesis. Proc. Natl. Acad. Sci. U. S. A. 81: 4586-4590.

Daniels, J. D., J. D. Pettigrew, and J. L. Norman (1978) Development of single-neuron responses in kitten's lateral geniculate nucleus. J. Neurophysiol. 41: 1373-1393

Dingledine, R., and J. S. Kelly (1977) Brain stem stimulation and the acetylcholine-evoked inhibition of neurones in the feline nucleus reticularis thalami. J. Physiol. (Lond.) 271: 135-154.

Dolabela di Lima, A., and W. Singer (1985) The cholinergic innervation of the visual thalamus. Exptl. Brain Res., in press.

Dubin, M. W., and B. G. Cleland (1977) Organization of visual inputs to interneurons of lateral geniculate nucleus of the cat. J. Neurophysiol. 40: 410-427.

Edwards, S. B., and J. S. DeOlmos (1976) Autoradiographic studies of the projections of the midbrain reticular formation: Ascending projections of nucleus cuneiformis. J. Comp. Neurol., 165: 417-431.

Ferster, D., and S. LeVay (1978) The axonal arborizations of lateral geniculate neurons in the striate cortex of the cat. J. Comp. Neurol. 182: 923-944.

Friedlander, M. J., C. -S. Lin, and S. M. Sherman (1979) Structure of physiologically identificd $X$ and $Y$ cells in the cat's lateral geniculate nucleus. Science 204: 1114-1117.

Friedlander, M. J., C. -S. Lin, L. R. Stanford, and S. M. Sherman (1981) Morphology of functionally identified neurons in lateral geniculate nucleus of the cat. J. Neurophysiol. 46: 80-129.

Frigyesi, T. L., and R. Schwartz (1972) Cortical control of sensorimotor relay activities in the cat and the squirrel monkey In Corticothalamic Projections and Sensorimotor Activities: Proceedings, T. L. Frigyesi, E. Rinvik, and M. D. Yahr, eds. pp. 161-195, Raven Press, New York

Graybiel, A. M., and R. P. Elde (1983) Somatostatin-like immunoreactivity characterizes neurons of the nucleus reticularis thalami in the cat and monkey. J. Neurosci, 3: 1308-1321.

Hale, P. T., A. J. Sefton, L. A. Baur, and L. J. Cottee (1982) interrelations of the rat's thalamic reticular and dorsal lateral geniculate nuclei. Exp. Brain Res. 45: 217-229.

Hendrickson, A. E., M. P. Ogren, J. E. Vaughn, R. P. Barber, and J. -Y. Wu (1983) Light and electron microscopic immunocytochemical localization of glutamic acid decarboxylase in monkey geniculate complex: Evidence for GABAergic neurons and synapses. J. Neurosci. 3: 1245-1262.

Hendry, S. C.H., E. G. Jones, and P. C. Emson (1984) Morphology, distribution, and synaptic relations of somatostatin- and neuropeptide $Y$-immunoreactive neurons in rat and monkey neocortex. J. Neurosci. 4: 24972517.

Houser, C. R., J. E. Vaughn, R. P. Barber, and E. Roberts (1980) GABA neurons are the major cell type of the nucleus reticularis thalami. Brain Res, 200: 311-351

Ide, L. S. (1982) The fine structure of the perigeniculate nucleus in the cat. J. Comp. Neurol. 210: 317-334.

Jasper, H. H. (1960) Unspecific thalamocortical relations. In Handbook of Physiology, Section 1; Neurophysiology, Vol. 2, J. Field, H. W. Magoun, and V. E. Hall eds., pp. 1307-1321, American Physiol. Soc. Washington, D.C.

Jones, E. G. (1975) Some aspects of organization of the thalamic reticular complex. J. Comp. Neurol. 162: 285-308

Jones, E. G. (1985) The Thalamus, Plenum Press, New York.

Kelly, J. S., J. -M. Godfraind, and S. Maruyama (1979) The presence and nature of inhibition in small slices of the dorsal lateral geniculate nucleus of rat and cat incubated in vitro. Brain Res. 168: 388-392.

Kölliker, A., von (1896) Handbuch der Gewebelehre des Menschen. Ed. 6 , Vol. 2: Nervensystem des Menschen und der Thiere, W. Engelmann, Leipzig.

Lindström, S. (1982) Synaptic organization of inhibitory pathways to principal cells in the lateral geniculate nucleus of the cat. Brain Res. 234: 447-453.

Minderhoud, J. M. (1971) An anatomical study of the efferent connections of the thalamic reticular nucleus. Exp. Brain Res. 12: 435-446.

Montero, V. M. (1983) Ultrastructural identification of axon terminals from the thalamic reticular nucleus in the medial geniculate body of the rat: An EM autoradiographic study. Exp. Brain Res. 51: 338-342.

Montero, V. M., and G. L. Scott (1981) Synaptic terminals in the dorsal lateral geniculate nucleus from neurons of the thalamic reticular nucleus: A light and electron microscopic autoradiographic study. Neuroscience 6: 25612577.

Montero, V. M. and Singer, W. (1984) Ultrastructure and synaptic relations of reural elements containing glutamic acid decarboxylase (GAD) in the perigeniculate nucleus of the cat. Exptl. Brain Res. 56: 115-125.

Montero, V. M., R. W. Guillery, and C. N. Woolsey (1977) Retinotopic organization within the thalamic reticular nucleus demonstrated by a double label autoradiographic technique. Brain Res. 138: 407-422.

Nissl, F. (1913) Die Grosshirnanteile des Kaninchens. Arch. Psychiat. NervKrankh. 52: 867-953.

Oertel, W. H., A. M. Graybiel, E. Mugnaini, R. P. Elde, and D. E. Schmechel, and I. J. Kopin (1983) Coexistence of glutamic acid decarboxylase- and somatostatin-like immunoreactivity in neurons of the feline nucleus reticularis thalami. J. Neurosci. 3: 1322-1332.

Ohara, P. T., and A. R. Lieberman (1981) Thalamic reticular nucleus: Arralurmical evidence that cortico-reticular axons establish monosynaptic contact with reticulo-geniculate projection cells. Brain Res. 207: 153-156.

Ohara, P. T., A. J. Sefton, and A. K. Lieberman (1980) Mode of termination of afferents from the thalamic reticular nucleus in the dorsal lateral geniculate nucleus of the rat. Brain Res. 197: 503-506.

Ohara, P. T., A. R. Lieberman, S. P. Hunt, and J-Y. Wu (1983) Neura elements containing glutamic acid decarboxylase (GAD) in the dorsa lateral geniculate nucleus of the rat: Immunohistochemical studies by light and electron microscopy. Neuroscience 8: 189-211.

Penny, G. R., D. Fitzpatrick, D. Schmechel, and I. T. Diamond (1983) Glutamic acid decarboxylasc immunorcactive neurons and horseradish peroxidaselabeled projection neurons in the ventral posterior nucleus of the cat and Galago senegalensis. J. Neurosci. 3: 1868-1887

Pullir, B., and R. Rokyta (1982) Somatotopic organization of nucleus reticularis thalami in chronic awake cats and monkeys. Brain Res. 250: 211221.

Ramón y Cajal, S. (1911) Histologie du Système Nerveux de l'Homme et des Vertébrés, L. Azoulay, transl., A. Maloine, Paris.

Rose, J. E. (1952) The cortical connections of the reticular complex of the thalamus. Res. Publ. Assoc. Nerv. Ment. Dis. 30: 454-479. 
Sanderson, K. J. (1971) The projection of the visual field to the latera geniculate and medial interlaminar nuclei in the cat. J.Comp. Neurol. 113 101-118.

Scheibel, M. E., and A. B. Scheibel (1966) The organization of the nucleus reticularis thalami: A Golgi study. Brain Res. 1: 43-62.

Schlag, J., and M. Waszak (1971) Characteristics of unit response in nucleus reticularis thalami. Brain Res. 32: 79-97

Schmielau, F. (1979) Integration of visual and nonvisual information in nucleus reticularis thalami of the cat. In Developmental Neurobiology, R. D. Freeman, ed., pp. 205-226, Plenum Press, New York.

Shosaku, A., and I. Sumitomo (1983) Auditory neurons in the rat thatamic reticular nucleus. Exp. Brain Res. 49: 432-442.

Shosaku, A., Y. Kayama, and I. Sumitomo (1984) Somatotopic organization in the rat thalamic reticular nucleus. Brain Res. 311: 57-64.

So, Y. T., and R. Shapley (1981) Spatial tuning of cells in and around latera geniculate nucleus of the cat: $X$ and $Y$ relay cells and perigeniculate interneurons. J. Neurophysiol. 45: 107-120.

Spreafico, R., D. E. Schmechel, L. C. Ellis, Jr., and A. Rustioni (1983) Cortical relay neurons and interneurons in the $N$. ventralis posterolateralis of cats: A horseradish peroxidase, electron-microscopic, Golgi and immunocyto chemical study. Neuroscience 9: 491-510.

Stanford, L. R., M. J. Friedlander, and S. M. Sherman (1983) Morphological and physiological properties of geniculate $W$-cells of the cat: A comparison with $X$ - and $Y$-cells. J. Neurophysiol. 50: 582608.

Steriade, M. (1978) Cortical long-axoned cells and putative interneurons during the sleep waking cycle. Behav. Brain Sci. 3: 465-514.

Steriade, M. (1983) The excitatory-inhibitory response sequence of Ihalaric and cortical neurons: State related changes and regulatory systems. In Dynamic Aspects of Neocortical Function, G. Edelman, W. E. Gall and W. M. Cowan, eds., pp. 10\%-158, John Wiley \& Sons, Inc., New York

Steriade, M., and P. Wyzinski (1972) Cortically elicited activities in thalamic reticularis neurons. Brain Res. 42: 514-520.

Sugitani, M. (1979) Electrophysiological and sensory properties of the tha lamic reticular neurons related to somatic sensation in rats. J. Physiol. (Lond.) 290: 79-95

Sumitomo, I., M. Nakamura, and K. Iwana (1976) Location and function of the so-called interneurons of the rat lateral geniculate body. Exptl. Neurol. 51: 110-173.

Yen, C. - T., and E. G. Jones (1983) Intracellular staining of physiologically identified neurons and axons in the somatosensory thalamus of the cat Brain Res. 280: 148-154.

Yen, C. T., M. Conley, and E. G. Jones (1985) Morphological and functional types of neurons in cat ventral posterior thalamic nucleus. J. Neurosci. 5: 1315-1337. 